\title{
Análise Comparativa da Evolução das Vendas e do PIB Per Capita dos Principais Mercados da Sétima Geração de Consoles de Videogames no Período de 2006-2011
}

\section{Comparative Analysis on the Evolution of Sales and PIB Per Capita in the Main Market of the Seventh Generation of Video Game Consoles in the Period 2006-2011}

\author{
Nelson Guilherme Machado Pinto \\ Mestrando do Programa de Pós-Graduação em Administração da Universidade Federal de Santa Maria. \\ Endereço: Rua Barão do Triunfo, n.1465, apt. 303, Bairro № Sr ${ }^{\text {a }}$ de Fátima, CEP 97015-070, Santa Maria-RS-Brasil, \\ e-mail: nelguimachado@hotmail.com
}

\section{Daniel Arruda Coronel}

Doutor em Economia Aplicada pela Universidade Federal Viçosa (UFV). Professor Adjunto do Programa de Pós-Graduação em Administração da UFSM. Endereço: Silva Jardim, 609, Bairro: Centro, CEP:97010-491. Santa Maria-RS, Brasil. e-mail: daniel.coronel@uol.com.br

\section{Róger Pase Bresolin}

Graduando em Administração pela Universidade Federal de Santa Maria.

Endereço: Rua Tamanday, nº.195, Bloco J apt. 401, Bairro Nonoai, CEP 97060-540. Santa Maria-RS, Brasil. e-mail: rogerbresolin@aol.com

RESUMO

O mercado de videogames está em constante inovação, sendo divido em gerações. Assim, o objetivo geral do trabalho é verificar o impacto do Produto Interno Bruto (PIB) per capita sobre a evolução das vendas da sétima geração de consoles de mesa nas principais regiões consumidoras dessa indústria, no período de 2006 a 2011 . A fim de verificar a influência do PIB per capita sobre a evolução desses mercados, foi utilizada uma adaptação do modelo de regressão aplicado por Alvarez, Fávero e Luppe (2007). O console da Nintendo pode ser considerado o "vencedor" dessa geração no período estudado, fato consequente da estratégia adotada pela empresa para essa geração. Os resultados do modelo demonstram uma satisfatória significância estatística dos coeficientes nas regressões realizadas e um alto poder de ajuste, verificando que o PIB per capita tem impacto nas vendas dos consoles da sétima geração de videogames em seus principais mercados.

Palavras-chave: Sétima Geração. Consoles de Videogame. PIB per capita.

\footnotetext{
${ }^{1}$ Artigo recebido em 05.06.2013. Revisado pelos pares em 31.07.2013 (blind review). Ajustado e Aceito para publicação em 06.08.2013. Recomendado para publicação por José Ribamar Marques de Carvalho (Editor Científico). Publicado em 15.09.2013. Organização responsável UACC/CCJS/UFCG.
} 


\section{ABSTRACT}

Video game market is constantly innovating and it is divided into generations. Thus, the overall goal of this work is to verify the impact of the Gross Domestic Product (GDP) per capita on the evolution of sales concerning tabletop video game consoles in the main consumer regions in the period 2006-2011. With the aim of verifying the GDP per capita of these market evolutions it was used a regression model adaptation applied by Alvarez, Fávero and Luppe (2007). The Nintendo console can be considered the "winner" in this generation in the studied period, which is a consequence of the strategy adopted by the company for this generation. The model results show a satisfactory statistical significance of the coefficients in the regressions performed and a high power setting verifying that GDP per capita has impact on seventh generation of video game consoles in their main markets.

Keywords: Seventh Generation. Video Game consoles. GDP per capita

\section{INTRODUÇÃO}

Os videogames passaram de um simples passatempo de jovens de engenharia, na década de 1950, para, atualmente, serem a mais poderosa das indústrias que lidam com produtos ligados à diversão (BELLI; RAVENTÓS, 2008). Assim, desde a metade do século passado até os dias atuais, esse setor passou por diversas inovações, formando um mercado sólido que movimenta uma grande quantidade de capitais.

O setor de diversões, tanto eletrônica como convencional, possui uma grande concorrência e, para isso, as empresas do setor devem se adaptar e planejar as futuras ações para terem longevidade no mercado (CRUZ JÚNIOR; BAUMGARTEN; PEREIRA, 2008). O mercado de videogames proporcionou a criação de uma indústria sólida. Assim, há mais de quarenta anos, esses produtos oferecem diversão e entretenimento ao ser humano (FRÍAS, 2010; VIAN; MACEDO, 2011).

Para Matsui e Colombo (2007), o videogame, juntamente com o computador e a internet, transformaram o ambiente da atual sociedade, visto que esses três elementos são baseados em tecnologia de manipulação virtual e também em ênfase de interação com o usuário. Por isso, os consoles de videogame fazem parte da realidade de grandes mercados consumidores e são objetos de consumo de muitos indivíduos.

O crescimento e a relevância que os videogames foram ocupando nas indústrias e na sociedade fizeram despertar o interesse de diversos pesquisadores em estudar esse produto, seus impactos e demais aspectos. Assim, analisar certas perspectivas do mercado dos videogames torna-se relevante devido à importância e ao impacto que estes produtos geram na atual sociedade. De acordo com Pinheiro (2008) e Fontenelle (2005), a temática dos games fez com que uma série de pesquisadores elevasse esse assunto sob o prisma de diversas áreas, fazendo surgir os chamados gamestudies.

Entretanto, ainda são escassos os trabalhos quantitativos ligados ao tema nas ciências sociais aplicadas. Existe uma série de estudos que têm a finalidade de 
mostrar uma evolução desse mercado ou então levantar alguns aspectos estratégicos, culturais e socioeconômicos ligados às atividades e às empresas desse setor (FONTENELLE, 2005; DÍEZ, 2006; BATISTA et al., 2007; MATSUI; COLOMBO, 2007; BELI; RAVENTÓS, 2008; CRUZ JUNIOR; BAUMGARTEM; PEREIRA, 2008; ETXEBERRIA, 2008; PINHEIRO, 2008; FRÍAS, 2010; VIAN; MACEDO, 2011; MONTEIRO, 2011; BRASIL, 2012). A busca do conhecimento da relação de aspectos quantitativos como níveis econômicos e de renda demonstram-se importantes no avanço da problemática epistemológica dessa área de estudo.

Dessa maneira, o objetivo geral do trabalho é verificar o impacto do Produto Interno Bruto (PIB) per capita sobre a evolução das vendas da sétima geração de consoles de mesa nas principais regiões consumidoras dessa indústria, no período de 2006 a 2011. Como objetivos específicos, o estudo pretende verificar qual console vendeu mais unidades a cada ano e analisar a evolução de mercado dos consoles da sétima geração nos principais mercados consumidores. A partir disso, a hipótese do estudo é de que o aspecto econômico tem influência diretamente proporcional à evolução de consoles das regiões de estudo. Isso porque, por serem regiões desenvolvidas e grandes consumidoras desse mercado, espera-se que o grande poder aquisitivo dessas localidades alavanque o crescimento desse mercado no período estudado.

Com a finalidade de atingir esses objetivos, o presente estudo está estruturado em quatro seções, além dessa introdução. Na segunda, é apresentado o referencial teórico; na seção seguinte, descrevem-se os procedimentos metodológicos utilizados; na quarta seção, os resultados são analisados e discutidos e, por fim, apresentam-se as principais conclusões do trabalho.

\section{FUNDAMENTAÇÃO TEÓRICA}

Neste capítulo há uma exposição dos principais temas do trabalho, isto é, os consoles de mesa. Procura-se também conhecer cada um dos componentes da sétima geração de consoles e as empresas responsáveis por sua produção. Por fim, há uma explanação das evidências empíricas relacionadas ao tema dos consoles.

\subsection{O Console de Mesa e a Sétima Geração}

Um console de videogame de mesa tem como objetivo executar softwares de jogos de vídeo e é caracterizado como um computador otimizado nos seus componentes internos e externos. É uma tecnologia que consiste em três elementos: armazenamento/transporte de software, o hardware (CPU) e os controles operacionais (FRÍAS, 2010). De acordo com Brasil (p.16, 2012), os videogames "sempre foram 'reféns' dos avanços das tecnologias". Um fato a se destacar é que a 
origem dessa indústria teve o envolvimento do aspecto lúdico com a guerra (FONTENELLE, 2005).

Neste sentido, conforme a indústria foi se consolidando, diferentes empresas foram lançando seus consoles de mesa e os videogames lançados no decorrer desses tempos foram agrupados em gerações que determinam o período de duração de diversos consoles que disputaram o mercado em certo espaço de tempo. Essas gerações marcam a constante obsolescência característica do setor, na qual a geração seguinte procura inovar tecnologicamente em relação à geração anterior (FRÍAS, 2010).

A sétima geração de consoles de mesa teve início em novembro de 2005 com o lançamento do Xbox 360, o primeiro videogame da geração a entrar no mercado. $\mathrm{O}$ ano de 2006 ficou marcado pela entrada dos outros dois consoles dessa geração. $O$ Playstation 3 (PS3) e o Wii foram lançados em novembro de 2006, formando, dessa forma, o mercado de videogames da sétima geração.

Essa geração é marcada pelo suporte multimídia com aparelhos admitindo suporte a DVD, HD DVD e Blu-ray (BELLI; RAVENTÓS, 2008). Ademais, pode-se inferir que os consoles de mesa têm também como característica a constante inovação no modo de jogos, qualidade gráfica e jogabilidade online.

\subsection{Xbox 360, Wii e Playstation 3}

A Microsoft é a fabricante do Xbox 360 e é a empresa que está há menos tempo no setor, em comparação com os seus atuais concorrentes de consoles de mesa. A organização fundada por Bill Gates já era conhecida internacionalmente por trabalhar no ramo de softwares de computadores. Esse console foi o primeiro a ser lançado dessa nova geração e, além de melhorias em relação ao console antecessor e gráficos de altíssima qualidade, a Microsoft investiu bastante no seu serviço de rede visando uma experiência online aos seus consumidores (FRÍAS, 2010).

O Wii é fabricado pela empresa Nintendo. Essa organização é mundialmente conhecida no ramo dos jogos eletrônicos. É, dentre as três da atual geração, a que atua há mais tempo no setor, isto é, há mais de três décadas (FRÍAS, 2010). Esse console foi o último da sétima geração a ser lançado e começou a ser vendido aproximadamente após um ano do lançamento do Xbox 360. O Nintendo Wii foi originado do chamado "Project Revolution" e, devido ao insucesso e à perda da liderança nas gerações anteriores, buscou explorar novos mercados, visando tornar a concorrência irrelevante (CRUZ JÚNIOR; BAUMGARTEN; PEREIRA, 2008).

A revolução no comando do controle é, segundo Frías (2010), uma característica marcante desse console para o mercado. Além disso, essa revolução fez com que as empresas concorrentes lançassem projetos realizados após o lançamento 
do Wii para concorrer com a mesma ideia de jogabilidade desse console (o Kinect para o Xbox 360 e o Playstation Move para Playstation 3).

Com a proposta de ser um produto diferente da concorrência, com o menor preço de lançamento da atual geração e buscando principalmente a inovação, o Wii mudou o paradigma de que "videogames são atividades solitárias e sedentárias". O fato de o videogame apresentar um sensor de movimento e a possibilidade de maior interação com o jogo fez o console da sétima geração da Nintendo atingir públicos de perfis pouco comuns entre os jogadores de jogos eletrônicos, como o público idoso e o feminino (BELLI; RAVENTÓS, 2008; CRUZ JÚNIOR; BAUMGARTEN; PEREIRA, 2008; MCCANN, 2013). Com isso, essas práticas demonstram a retomada do sucesso e do prestígio da Nintendo no mercado dos consoles de mesa.

Por último, o videogame da atual geração fabricado pela Sony abrange jogadores que são considerados "clássicos", ou seja, já jogam videogames há mais de uma geração e preferencialmente possuíram os consoles anteriores da empresa, ou seja, Playstation 1 e 2 (BELLI; RAVENTÓS, 2008). O PS3, de origem de fabricação japonesa, teve seu respaldo ligado principalmente ao sucesso de seus antecessores nas últimas gerações.

Esse console é o de preço mais elevado dessa geração, fato proporcionado pelos elementos que o console propôs-se a trazer para o seu público-alvo. Um exemplo disso foi a opção feita pela Sony pela utilização do formato Blu-Ray no Playstation 3, proporcionando uma grande capacidade de processamento (FRÍAS, 2010; MCCANN, 2013).

\subsection{Evidências Empíricas}

Os trabalhos empíricos relacionado ao tema dos videogames mostram uma escassez de trabalhos quantitativos relacionados ao tema na área de ciências sociais aplicadas. A maioria dos estudos relacionados abrange aspectos mais teóricos com relação a essa temática, como aspectos culturais, estratégicos e sociais, relacionando o tema com o estágio atual da sociedade (DÍEZ, 2006; MATSUI; COLOMBO, 2007; CRUZ JUNIOR; BAUMGARTEM; PEREIRA, 2008; ETXEBERRIA, 2008; PINHEIRO, 2008; MONTEIRO, 2011; VIAN; MACEDO, 2011; BRASIL, 2012). Além disso, existem estudos que buscam fazer um resgate da evolução desse mercado passando por todas as gerações de consoles e explanando a evolução ocorrida entre os diferentes cortes de tempo (FONTENELLE, 2005; BATISTA et al., 2007; BELI; RAVENTÓS, 2008; PINHEIRO, 2008; FRÍAS, 2010).

O trabalho de Fontenelle (2005), procura resgatar as origens desse mercado, contextualizando os primeiros anos dessa indústria. A partir de um resgate bibliográfico este estudo procura levantar questões do surgimento dessa indústria. Além disso, evidenciam-se os desdobramentos contemporâneos desse mercado, com 
a finalidade de compreender a lógica que sustenta essa indústria que movimento grandes quantias de dinheiro. De forma semelhante, os trabalhos de Batista et al. (2007) e Pinheiro (2008) resgatam a história da indústria de jogos eletrônicos. Os autores dos artigos apresentam a origem dessa indústria desde a origem dos laboratórios de pesquisa até o surgimento da primeira geração de consoles.

No mesmo foco dos estudos que têm o objetivo de fazer um resgate da evolução da indústria de videogames no decorrer dos anos e através das suas diferentes gerações, o estudo de Beli e Raventós (2008) faz esse resgate desde a metade do século passado até os dias atuais. Os autores conceituam os principais aspectos que envolvem esse mercado, além de fazer um resgate não apenas dos consoles nas diferentes gerações, mas também dos jogos eletrônicos e gêneros de jogos que fizeram sucesso nas diferentes épocas. Ademais, os autores trazem dados a fim de rechaçar a hipótese de que os jogos violentos impulsionam a indústria, mostrando dados para o mercado espanhol que demonstram que os principais jogos das diferentes gerações não tinham nenhum conteúdo violento. Por fim, os autores debatem o futuro dessa indústria nos próximos anos.

O estudo de Frías (2010), também tem uma preocupação de fazer um resgate da história dessa indústria. Entretanto, de maneira distinta, esse autor propõe-se a verificar as diversas inovações ocorridas no mercado de videogames a partir dos anos 70. Portanto, o trabalho verifica as principais inovações da indústria, bem como dos jogos eletrônicos e dos consoles fabricados pelas empresas do setor.

Há trabalhos que representam uma maior preocupação social com o tema de videogames. Um desses trabalhos é o de Díez (2006), no qual há uma explanação dos principais problemas que podem ocorrer com a utilização dos videogames na hora de lazer. O trabalho é focado no público jovem, pois, segundo o autor, o tempo livre dessa geração pode vir a fazer com que esses jovens utilizem essa ferramenta digital de maneira errada. Segundo o trabalho, os jovens devem utilizar os videogames como uma forma de educação, aproveitando os recursos apresentados por essa ferramenta.

Seguindo essa mesma linha, o estudo de Matsui e Colombo (2007), demonstra a preocupação social de pais e educadores no uso intensivo dos videogames por públicos, principalmente jovens. $O$ estudo traz um resgate social e também econômico dessa utilização massiva de jogos eletrônicos por uma geração. Dessa maneira, o estudo demonstra as diferentes relações de identidade entre determinadas gerações do homem com a evolução da indústria de jogos.

A preocupação com a violência dos jogos sobre as atitudes dos jovens também ganha destaque no trabalho de Etxeberria (2008). De acordo com as ideias do autor, essa temática é um dos principais assuntos abordados na literatura dos efeitos do videogame sobre a conduta das crianças. De maneira semelhante ao encontrado em outros estudos, os autores reforçam a ideia de preocupação de pais e educadores 
sobre os jogos violentos, além de procurar aproveitar as ferramentas educacionais proporcionadas por essa indústria.

Existem trabalhos que procuram verificar a importância dessa indústria dentro do contexto socioeconômico mundial. Assim, o estudo de Vian e Macedo (2011) procura fazer um debate sobre os efeitos dos jogos sobre a sociedade. Além disso, também resgatam temas salientados por outros autores, como preocupações pedagógicas, por exemplo. O trabalho de Brasil (2012), busca evidenciar a importância dos jogos eletrônicos na área do jornalismo. Além disso, o autor faz uma proposta de utilização de jogos como recursos didáticos de ensino, mostrando que essa questão evidencia-se como uma preocupação presente na literatura.

Por último, há evidências empíricas que focam em empresas ou consoles de destaque em determinadas gerações. Um exemplo disso é o estudo de Cruz Júnior, Baumgartem e Pereira (2008), os quais verificaram as melhores práticas da gigante do setor Nintendo. $\mathrm{O}$ estudo faz um resgate teórico da empresa, desde as suas origens até a sua evolução. $\mathrm{O}$ trabalho dos autores foca-se também na perda de mercado da empresa em algumas gerações até a retomada da liderança pelo seu console Wii através de uma análise das estratégias adotadas pela empresa para reverter esse cenário. Outro trabalho que segue essa temática é o estudo de Monteiro (2008), o qual faz uma exposição da relação entre jogos eletrônicos e eventos históricos.

\section{PROCEDIMENTOS METODOLÓGICOS}

O presente trabalho foi realizado sob um caráter quantitativo e descritivo, pois houve uma avaliação dos números em relação à venda de consoles de videogame e ao PIB per capita dos principais mercados a fim de conhecer a realidade destes. Com o objetivo de analisar os principais mercados de videogames, as informações mais relevantes referentes ao mercado de jogos foram retiradas do Video Game Chartz, uma empresa especializada em pesquisas e inteligência de negócios relacionados à indústria dos videogames. A partir disso, ficaram conhecidas como os principais mercados da sétima geração de consoles as seguintes localidades: Estados Unidos, Japão e Europa. Estas três regiões representam 85,86\% do mercado mundial dos consoles da sétima geração de videogames para o período de estudo (VIDEOGAME CHARTZ, 2013).

Para verificar a influência das variáveis socioeconômicas sobre a evolução desse mercado, foi utilizado um dos parâmetros do modelo de regressão aplicado por Alvarez, Fávero e Luppe (2007) nas principais redes varejistas mundiais. O modelo de regressão consiste em estudar a dependência de uma variável, denominada dependente em relação a uma ou mais variáveis, denominadas explicativas ou independentes (GREENE, 2008). Assim, é possível verificar se a 
relação entre variáveis é forte ou fraca, permitindo inferir quais variáveis possuem maior identidade entre si.

Adaptando do modelo de Alvarez, Fávero e Luppe (2007) a variável dependente para o estudo em questão e utilizando o Produto Interno Bruto (PIB) per capita como variável independente, a análise de regressão utilizada neste trabalho pode ser definida como:

$$
\triangle \text { Vendas }=\beta_{0}+\beta_{1} * P I B p+\mu_{i}
$$

em que:

$\Delta$ Vendas $=$ Variação das vendas de console da sétima geração na região

$\beta_{0}=$ coeficiente angular

$\beta_{1}=$ parâmetro

$P I B p=$ PIB per capita na região

$\mu_{i}=$ termo de erro aleatório

Os testes estatísticos foram realizados no software Gnu Regression, Econometrics and Time-series Library (GRETL). O modelo regressivo utilizado neste estudo foi estimado pelo Método dos Mínimos Quadrados (MQO), o qual apresenta algumas propriedades estatísticas relevantes que o qualificam como um dos métodos de análise de regressão mais utilizados e poderosos (GREENE, 2008). Devido ao pequeno período de tempo analisado, não foi possível utilizar os demais parâmetros do modelo utilizado. Cabe destacar que a aplicação do modelo regressivo foi realizada separadamente para cada um dos três mercados estudados e em cada um dos três tipos de console da sétima geração. A análise de regressão do presente estudo buscou num primeiro momento ajustar-se aos pressupostos que devem nortear o método de mínimos quadrados de uma regressão, isto é, ser linear nos parâmetros; apresentar valores das variáveis independentes fixos ou sem nenhuma relação com o termo de erro; apresentar zero como valor médio do termo de erro; apresentar homocedasticidade constante do termo de erro e inexistência de autocorrelação entre os termos de erro; ter o número de observações maior que o número de parâmetros a serem estimados e, por fim, necessitarem ter variabilidade os valores das variáveis independentes (GREENE, 2008).

Foi utilizado, para fins da pesquisa, o ranking de vendas de consoles publicado pela Video Game Chartz. O ranking traz as vendas dos consoles da sétima geração por ano desde o seu início, isto é, 2005, com relação ao mundo todo, além de fazer esse mesmo ranking nos três principais mercados de games: Estados Unidos, Europa e Japão. 
Neste trabalho, foi utilizado o ranking trimestral das vendas desses principais mercados entre os anos de 2006 e 2011, totalizando 24 observações para cada país. Os dados referentes ao PIB per capita foram coletados também trimestralmente da base de dados do Banco Mundial, para o mesmo período de análise.

Num primeiro momento, foram verificadas a evolução das vendas, a taxa de crescimento e as estatísticas descritivas das variáveis estudadas. Ademais, foi verificada a correlação entre as vendas dos consoles nos principais mercados com o PIB per capita. Essa técnica de maneira distinta da análise de regressão preocupa-se em apenas medir a força ou o grau de associação entre duas variáveis sem determinar qualquer relação de dependência. A fim de verificar se os dados da regressão apresentavam problemas quanto aos seus pressupostos, verificaram-se os problemas de heterocedasticidade e autocorrelação, por meio da realização dos testes de White e Durbin-Watson, respectivamente. Para este estudo, os dados apresentaram tais tendências e, para isso, foi necessário realizar a regressão por MQO com erros-padrões consistentes com heterocedasticidade e autocorrelação (HAC) (GREENE, 2008).

\section{ANÁliSE E DISCUSSÃO DOS RESULTADOS}

Nesta seção, são apresentados e discutidos os principais resultados do trabalho. Num primeiro momento, há uma apresentação da evolução do mercado de jogos no período de estudo. Posteriormente, são analisadas as influências do PIB per capita nos três países objeto de estudo.

\subsection{Evolução da Sétima Geração de Consoles 2006-2011}

Os três principais mercados consumidores de consoles de videogames são EUA, Europa e o Japão. Por serem importantes centros da economia mundial e destacadamente do ramo de eletrônicos, as vendas de consoles da sétima geração nesses mercados e suas respectivas tavas de crescimento no período de estudo podem ser observados na Tabela 1 e na Tabela 2, respectivamente:

Tabela 1 - Venda de Consoles da Sétima Geração 2006-2011

\begin{tabular}{l|l|l|l|l|l|l|l|l|l}
\hline Ano & \multicolumn{3}{|c|}{ EUA } & \multicolumn{3}{c}{ Europa } & \multicolumn{3}{c}{ Japão } \\
\hline & Wii & Xbox 360 & PS3 & Wii & Xbox 360 & PS3 & Wii & $\begin{array}{l}\text { Xbox } \\
360\end{array}$ & PS3 \\
\hline 2006 & 1.075 .329 & 3.832 .778 & 667.762 & 697.443 & 1.841 .797 & 0 & 958.199 & 200.291 & 472.605 \\
\hline 2007 & 6.444 .409 & 4.389 .044 & 2.450 .089 & 5.111 .302 & 2.026 .633 & 3.418 .547 & 3.677 .579 & 257.924 & 1.218 .612 \\
\hline 2008 & 9.826 .502 & 4.881 .772 & 3.477 .812 & 8.386 .493 & 3.926 .838 & 4.171 .686 & 3.018 .864 & 345.745 & 1.065 .808 \\
\hline 2009 & 8.989 .309 & 4.787 .281 & 4.172 .494 & 6.800 .377 & 3.399 .303 & 4.801 .065 & 2.020 .780 & 342.496 & 1.829 .784 \\
\hline
\end{tabular}


PINTO, N. G. M.; et al. Análise Comparativa da Evolução das Vendas e do PIB...

\begin{tabular}{l|c|c|c|c|c|c|c|c|c}
\hline 2010 & 7.398 .500 & 4.737 .437 & 6.999 .773 & 5.656 .366 & 4.089 .727 & 5.317 .220 & 1.661 .630 & 211.585 & 1.553 .638 \\
\hline 2011 & 4.878 .060 & 7.693 .050 & 4.486 .935 & 5.773 .324 & 4.155 .149 & 4.099 .457 & 875.543 & 114.959 & 1.521 .847 \\
\hline$\Sigma$ & 38.612 .109 & 30.321 .362 & 22.254 .865 & 32.425 .305 & 19.439 .447 & 21.807 .975 & 12.212 .595 & 1.473 .000 & 7.662 .294 \\
\hline
\end{tabular}

Fonte: Video Game Chartz.

O mercado americano teve, nos anos iniciais dessa $7^{a}$ geração, o predomínio nas vendas do Xbox 360, já que este foi o primeiro console da geração a ser lançado e, por consequência disso, foi o primeiro a ocupar um espaço de maior relevância nesse mercado, pois os outros dois consoles ainda estavam entrando no mercado (FRÍAS, 2010). Apenas para entender tal predomínio do console da Microsoft, é possível inferir que, em 2006, a cada 5 consoles vendidos no mercado americano, 3 eram do console da empresa fundada por Bill Gates. Entretanto, em 2007, com os três consoles consolidados no mercado, verifica-se o aumento considerável nas taxas de crescimento desses produtos, sendo destacado o crescimento considerável do Wii, tomando a frente com uma ampla vantagem em relação ao Xbox 360 e o PS3 e apresentando taxa de crescimento próxima à casa dos 500\% para esse ano.

Nos anos de 2008 e 2009, as posições no ranking de vendas continuam as mesmas, porém, nesse período, constata-se uma redução nas vendas do Xbox 360 . Tal fato fez com que o PS3 ultrapassasse o Xbox 360 no ranking geral em 2010, e assim o console da Sony passa a ocupar o segundo lugar no mercado, chegando a se aproximar do Wii em número de vendas nesse ano. Já em 2011, depois de um longo declínio nas vendas, o Xbox 360 aumenta consideravelmente as suas vendas e chega ao topo do mercado para esse ano, posto que não ocupava, desde o ano de 2006, com vantagem em relação aos demais. Nota-se, por último, no mercado americano, que o console da Nintendo atingiu seu auge nos anos de 2008 e 2009 e foi apresentando declínios nos dois anos posteriores.

Tabela 2 - Taxa de Crescimento dos Consoles da Sétima Geração (Wii, Xbox 360, PS3) no período de 2006-2011 para as principais regiões desse mercado

\begin{tabular}{c|c|c|c|c|c|c|c|c|c}
\hline Ano & \multicolumn{3}{|c|}{ EUA } & \multicolumn{3}{|c|}{ Europa } & \multicolumn{3}{c}{ Japão } \\
\hline & Wii (\%) & $\begin{array}{c}\text { Xbox 360 } \\
(\%)\end{array}$ & PS3 (\%) & Wii (\%) & $\begin{array}{c}\text { Xbox 360 } \\
(\%)\end{array}$ & $\begin{array}{c}\text { PS3 } \\
(\%)\end{array}$ & Wii (\%) & $\begin{array}{c}\text { Xbox 360 } \\
(\%)\end{array}$ & PS3 (\%) \\
\hline 2007 & $499,30 \%$ & $14,51 \%$ & $266,91 \%$ & $632,86 \%$ & $10,04 \%$ & $0,00 \%$ & $283,80 \%$ & $28,77 \%$ & $157,85 \%$ \\
\hline 2008 & $52,48 \%$ & $11,23 \%$ & $41,95 \%$ & $64,08 \%$ & $93,76 \%$ & $22,03 \%$ & $-17,91 \%$ & $34,05 \%$ & $-12,54 \%$ \\
\hline 2009 & $-8,52 \%$ & $-1,94 \%$ & $19,97 \%$ & $-18,91 \%$ & $-13,43 \%$ & $15,09 \%$ & $-33,06 \%$ & $-0,94 \%$ & $71,68 \%$ \\
\hline 2010 & $-17,70 \%$ & $-1,04 \%$ & $67,76 \%$ & $-16,82 \%$ & $20,31 \%$ & $10,75 \%$ & $-17,77 \%$ & $-38,22 \%$ & $-15,09 \%$ \\
\hline 2011 & $-34,07 \%$ & $62,39 \%$ & $-35,90 \%$ & $2,07 \%$ & $1,60 \%$ & $22,90 \%$ & $-47,31 \%$ & $-45,67 \%$ & $-2,05 \%$ \\
\hline
\end{tabular}

Fonte: Elaboração dos autores.

No mercado europeu, o parâmetro inicial é praticamente o mesmo encontrado no mercado dos Estados Unidos, com a diferença de que, no ano de 2006, o PS3 não era comercializado na Europa, entrando apenas nesse mercado no ano de 2007. Em 
2006, o Xbox começou liderando o mercado, contudo, a partir do ano de 2007, com a consolidação do Wii, este assumiu a liderança, destacando-se também nesse ano a inserção do PS3, que conquista o posto de segundo lugar no mercado. É importante observar que a maior taxa de crescimento encontrada em todos os mercados ocorreu nesse mercado, para o ano de 2007, isto é, o Nintendo Wii alcançou incríveis 633\% para esse mercado, demonstrando o fenômeno que esse console foi para essa geração (CRUZ JÚNIOR; BAUMGARTEN; PEREIRA, 2008).

Até o ano de 2010, o mercado mantém a sua tendência, porém o PS3 ficou bem próximo em número de vendas com o console da Nintendo e este, assim como no mercado americano, mostrou um declínio após atingir o pico do mercado. No ano de 2011, o Wii tem seu declínio suspendido com um pequeno crescimento no mercado e é possível perceber que o Xbox 360 ultrapassa o PS3, tornando-se o segundo console mais vendido no mercado europeu nesse ano. Avaliando em um âmbito geral, podese conjecturar que o Wii teve grande domínio no mercado europeu, mas que, aos poucos, essa vantagem foi diminuindo.

Com relação ao mercado japonês, desde o início da $7^{a}$ geração, os consoles da Nintendo e da Sony se mantiveram sempre à frente do Xbox 360, fato que pode retratar a preferência dos japoneses pelas duas empresas de origem nacional, em detrimento da empresa americana fabricante do Xbox 360. Em 2006, já era possível perceber a ampla vantagem do Wii em relação aos seus concorrentes e, no ano seguinte, essa diferença é aumentada, chegando o Wii a vender praticamente o dobro que seu concorrente mais próximo, isto é, o console fabricado pela Sony. No ano de 2008, apesar de uma redução na vendas do console da Nintendo, tal tendência se mantém.

A partir do ano de 2009, o PS3 começa uma reação no mercado, mantendo-se próximo no número de unidades vendidas do Wii, que segue uma tendência de taxas de crescimento negativas. A liderança de mercado do PS3 chega em 2011, quando este ultrapassa o console da Nintendo. Dessa forma, com relação ao Japão, verifica-se que o Xbox 360 não tem uma participação relevante dentro desse mercado, pois obteve leves crescimentos nos anos de 2007 e 2008, mas esse aumento representou muito pouco em relação às unidades vendidas por seus concorrentes. Constata-se certa resistência ao console vindo de outra origem nacional, visto que as outras duas empresas que são de origem japonesa são favorecidas nesse mercado, principalmente por estarem na sua praça de origem. Além disso, nesse mercado, o Nintendo Wii teve apenas uma taxa de crescimento positiva, porém, como também nos outros dois mercados, o console da Nintendo pode ser considerado o "vencedor" dessa geração no período estudado, pois teve o maior número no somatório das vendas para os três mercados. Esse fato encontra justificativa na estratégia tomada pela Nintendo em relação ao Wii, o qual tinha a proposta de ser um produto diferente, de menor preço e com grande inovação, mudando o paradigma que estava vigente nesse mercado 
PINTO, N. G. M.; et al. Análise Comparativa da Evolução das Vendas e do PIB...

(BELLI; RAVENTÓS, 2008; CRUZ JÚNIOR; BAUMGARTEN; PEREIRA, 2008; MCCANN, 2013).

\subsection{Análise da Influência do PIB per capita dos Principais Mercados}

Antes de aplicar o modelo de regressão utilizado no estudo, verifica-se a estatística descritiva das variáveis estudadas nos diferentes mercados na Tabela 3:

Tabela 3 - Estatística Descritiva das Variáveis

\begin{tabular}{c|l|l|l|l|l|l}
\hline \multirow{2}{*}{ País } & \multirow{2}{*}{ Variável } & \multicolumn{5}{|c}{ Estatística Descritiva } \\
\cline { 3 - 7 } & & \multicolumn{1}{|c|}{ Média } & \multicolumn{1}{c}{ Mediana } & \multicolumn{1}{c}{ Máximo } & \multicolumn{1}{c}{ Mínimo } & \multicolumn{1}{c}{ Desvio-padrão } \\
\hline \multirow{4}{*}{ EUA } & Wii & $6.435 .351,50$ & $6.921 .454,50$ & 9.826 .502 & 1.075 .329 & $3.165 .606,92$ \\
\cline { 2 - 7 } & Xbox 360 & $5.430 .616,33$ & $4.834 .526,50$ & 7.693 .050 & 3.832 .778 & $1.544 .922,61$ \\
\cline { 2 - 7 } & PS3 & $3.332 .088,17$ & $3.825 .153,00$ & 4.737 .437 & 667.762 & $1.543 .551,12$ \\
\cline { 2 - 7 } & PIBp & $46.293,39$ & $46.480,55$ & 48.112 & 44.623 & $1.216,33$ \\
\hline \multirow{5}{*}{ Europa } & Wii & $5.125 .239,67$ & $5.383 .834,00$ & 8.386 .493 & 697.443 & $2.622 .279,97$ \\
\cline { 2 - 7 } & Xbox 360 & $3.239 .907,83$ & $3.663 .070,50$ & 4.155 .149 & 1.841 .797 & $1.047 .271,56$ \\
\cline { 2 - 7 } & PS3 & $3.913 .640,33$ & $4.486 .375,50$ & 5.773 .324 & 0 & $2.090 .180,25$ \\
\cline { 2 - 7 } & PIBp & $37.480,32$ & $37.581,17$ & 41.075 & 32.984 & $2.745,12$ \\
\hline \multirow{5}{*}{ Japão } & Wii & $2.035 .432,50$ & $1.841 .205,00$ & 3.677 .579 & 875.543 & $1.123 .343,34$ \\
\cline { 2 - 7 } & Xbox 360 & $245.500,00$ & $234.754,50$ & 345.745 & 114.959 & $89.271,13$ \\
\cline { 2 - 7 } & PS3 & $1.277 .049,00$ & $1.370 .229,50$ & 1.829 .784 & 472.605 & $476.888,10$ \\
\cline { 2 - 7 } & PIBp & $39.101,42$ & $38.722,80$ & 45.903 & 34.095 & $4.762,84$ \\
\hline
\end{tabular}

Fonte: Elaboração dos autores.

O modelo de regressão estimado pelo MQO consiste em uma análise de regressão simples, isto é, o modelo possui apenas uma variável independente. Assim, a regressão foi realizada nos três mercados e em seus três diferentes consoles, sendo estas a variável dependente do modelo, e relacionado-a com o PIB per capita dos diferentes mercados, o qual é classificado como variável independente.

Referente à correlação entre as variáveis, a partir da Tabela 4, verifica-se que a correlação entre as vendas dos consoles mostram-se diretamente proporcionais em todos os mercados, com exceção dos consoles Wii e Xbox 360 para o mercado japonês. Dessa forma, verifica-se na maioria dos mercados o alto grau de associação entre a venda dos consoles e o PIB per capita.

Tabela 4 - Correlação entre variáveis dependentes e PIB per capita para os principais mercados de console no período de 2006 a 2011

\begin{tabular}{c|c|c}
\hline \multicolumn{1}{c|}{ País } & Variáveis x PIB per capita & Correlação \\
\hline \multirow{2}{*}{ EUA } & Wii & 0,2850 \\
\cline { 2 - 3 } & Xbox 360 & 0,8095 \\
\cline { 2 - 3 } & PS3 & 0,6591 \\
\hline
\end{tabular}


PINTO, N. G. M.; et al. Análise Comparativa da Evolução das Vendas e do PIB...

\begin{tabular}{l|c|c}
\hline \multirow{3}{*}{ Europa } & Wii & 0,8095 \\
\cline { 2 - 3 } & Xbox 360 & 0,6388 \\
\cline { 2 - 3 } & PS3 & 0,7037 \\
\hline \multirow{3}{*}{ Japão } & Wii & $-0,4980$ \\
\cline { 2 - 3 } & Xbox 360 & $-0,4401$ \\
\cline { 2 - 3 } & PS3 & 0,6621 \\
\hline
\end{tabular}

Fonte: Elaboração dos autores.

Portanto, a partir disso, os resultados da análise de regressão baseado no modelo de estudo apresenta os seguintes resultados, conforme Tabela 5:

Tabela 5 - MQO do PIBp x Consoles da Sétima Geração, utilizando as observações trimestrais de 2006-2011 para os EUA, Europa e Japão com erros padrão HAC

\begin{tabular}{|c|c|c|c|c|c|c|c|}
\hline \multirow[t]{2}{*}{ País } & \multirow{2}{*}{$\begin{array}{c}\text { Variável } \\
\text { Dependente }\end{array}$} & \multicolumn{6}{|c|}{ Variável Independente $=$ PIBp } \\
\hline & & $\begin{array}{c}\text { Coeficiente } \\
\text { Angular }\end{array}$ & Parâmetro & $\begin{array}{c}\text { Erro } \\
\text { Padrão }\end{array}$ & $\begin{array}{c}\text { razão- } \\
\mathbf{t}\end{array}$ & p-valor & $\mathbf{R}^{2}$ \\
\hline \multirow[t]{4}{*}{ EUA } & Wii & $-0,000002$ & 139,359 & 27,040 & 5,153 & $0,00360^{* * *}$ & \\
\hline & & & & & & & 0,836828 \\
\hline & Xbox 360 & $-0,000004$ & 117,832 & 14,089 & 8,363 & $0,00040^{* * *}$ & 0,945746 \\
\hline & PS3 & $-0,000003$ & 72,417 & 14,180 & 5,106 & $0,00375^{* * *}$ & 0,859189 \\
\hline \multirow[t]{3}{*}{ Europa } & Wii & $-0,000002$ & 139,578 & 24,211 & 5,765 & $0,00221^{* * *}$ & 0,859107 \\
\hline & Xbox 360 & $-0,000005$ & 87,142 & 10,389 & 8,387 & $0,00039^{* * *}$ & 0,939038 \\
\hline & PS3 & $-0,000001$ & 106,338 & 20,125 & 5,283 & $0,00323^{* * *}$ & 0,841680 \\
\hline \multirow[t]{3}{*}{ Japão } & Wii & $-0,000006$ & 49,985 & 12,852 & 3,889 & $0,01153^{* *}$ & 0,744478 \\
\hline & Xbox 360 & 0,568008 & 6,101 & 1,238 & 4,926 & $0,00437^{* * *}$ & 0,861078 \\
\hline & PS3 & $-0,000001$ & 33,070 & 3,2227 & 10,261 & $0,00015^{* * *}$ & 0,929920 \\
\hline
\end{tabular}

Fonte: Elaboração dos autores.

Notas: ${ }^{*}$ denota significância estatística para o valor do coeficiente: ${ }^{*} \mathrm{p}$-value $<10 \%$; ${ }^{* *} \mathrm{p}$-value $<5 \%$; $* * *$ p-value $<1 \%$

Por meio da análise da Tabela 5, verifica-se que há uma relação significativa entre a variável dependente e independente do modelo de regressão estimado. Isso pode ser observado na coluna que mede o p-valor que denota a significância estatística do coeficiente da regressão, o qual, a partir disso, possui condições de ser analisado. Portanto, observa-se que praticamente todas as análises realizadas foram significativas ao nível de 1\%. Apenas na regressão do Nintendo Wii para o mercado japonês a significância ficou no nível de 5\%, demonstrando uma satisfatória significância estatística dos coeficientes nas regressões simples realizadas.

Analisando os parâmetros de regressão encontrados, verifica-se a relação positiva entre PIB per capita e a variação das vendas dos principais consoles. Os maiores impactos em todos os mercados são para o Nintendo Wii, porém o mercado americano e o europeu são os que possuem uma maior variação na venda dos três consoles quando o PIB per capita é aumentado. Nos Estados Unidos, a cada aumento 
de US\$ 1,00 no PIB per capita, há um aumento aproximadamente de 139, 117 e 72 unidades de consoles vendidas de Wii, Xbox 360 e PS3, respectivamente. A Europa possui os maiores coeficientes para o console da Nintendo e da Microsoft, portanto, o aumento de US\$ 1,00 no PIB per capita provoca uma variação positiva nas vendas de console de aproximadamente 139, 87 e 106 de Wii, Xbox 360 e PS3, respectivamente. Por último, o mercado japonês mostrou-se o menos impactado com esta relação e, dessa forma, quando o PIB per capita tem um aumento de US\$1,00, há um aumento de aproximadamente 49, 6 e 33 unidades de consoles vendidas de Wii, Xbox 360 e PS3, respectivamente.

Outro parâmetro importante a ser estudado é o $\mathrm{R}^{2}$ que denota o poder de ajuste da regressão, isto é, quão "bem" uma regressão amostral é adequada aos dados utilizados (GREENE, 2008). Dessa maneira, observando a última coluna da Tabela 4, verifica-se o alto poder de ajuste das regressões realizadas. A fim de caracterizar a relevância desse resultado, basta contrapor o menor $\mathrm{R}^{2}$ encontrado, que foi de 0,744478 para o Wii no Japão, com o maior, que foi de 0,945746 para o Xbox 360 no mercado americano. Isso demonstra que o menor $\mathrm{R}^{2}$ encontrado nas análises de regressão realizadas é composto por um valor alto, chegando a valores ainda maiores para as outras regressões e passando em alguns casos o valor de 0,9.

Com isso, conjectura-se, a partir dos resultados encontrados, que o PIB per capita tem impacto e explica em grande parte as vendas dos consoles da $7^{\mathbf{a}}$ geração de videogames em seus principais mercados. De certa maneira, este resultado vai ao encontro dos pressupostos econômicos. Isso porque, por representar o poder aquisitivo médio de cada habitante de um país, o PIB per capita demonstra que há influência deste sobre as vendas nesse tipo de mercado. Esses resultados vêm a corroborar a hipótese do estudo, isto é, de que há uma relação positiva entre o nível de renda desses mercados e o poder aquisitivo da população residente nesses países.

\section{CONSIDERAÇÕES FINAIS}

O mercado de videogames é marcado, desde seu início, por um constante grau de inovação. Assim, os consoles de mesa dessa indústria são classificados por gerações conforme as inovações vão ocorrendo. No decorrer da evolução da indústria, grandes empresas de outros setores eletrônicos começam a fabricar esses produtos com o objetivo de comercializar nesse mercado concorrido, porém de muitas oportunidades.

A partir disso, a sétima geração de consoles é marcada por um grande salto de inovação em relação à geração anterior. Além disso, a concorrência nesse mercado passa a ser disputada por três grandes empresas. Essa disputa é marcada pela concentração de mais de $85 \%$ do mercado em três regiões, que são os mercados americano, europeu e japonês. 
Dessa forma, o sucesso de uma empresa durante essa geração passa pelo sucesso nesses mercados. Fica evidente o domínio do Nintendo Wii durante essa geração, nesses principais mercados, no período de 2006 a 2011. Tal sucesso faz o console da Nintendo ser o "vencedor" dessa geração e isso está diretamente relacionado à proposta que essa empresa teve ao lançar o Wii, isto é, de revolucionar o mercado de consoles.

O poder aquisitivo médio por indivíduo desses principais mercados representados pelo PIB per capita demonstram uma relação significativa e ajustada para esses mercados. Os mercados americano e europeu tiveram uma relação mais impactante na relação aumento do PIB per capita e aumento das vendas dos consoles, devido aos maiores coeficientes encontrados nesses mercados. Com altos índices de PIB per capita comparado a outros mercados mundiais, verifica-se que esse fator tem relação direta no cenário dos consoles da sétima geração de videogames para os mercados dos Estados Unidos, Europa e Japão, explicando em grande parte as variações das vendas de consoles nesses principais mercados.

Como limitações, o estudo apresenta o tamanho da amostra, o qual fez com que não fosse possível utilizar os demais parâmetros do modelo de estudo. Além disso, pelo PIB per capita não ser dado em valores mensais, a análise de regressão utilizou dados trimestrais. Para trabalhos futuros, sugere-se verificar se a relação com o PIB per capita continuará significativa nos anos que antecederão o lançamento da oitava geração de consoles, bem como ampliar o escopo deste estudo de consoles para as empresas fabricantes, isto é, estudar a evolução das vendas por empresas fabricantes, nas diferentes gerações de consoles.

\section{REFERÊNCIAS}

ALVAREZ, R. A. G.; FÁVERO, L. P. L.; LUPPE, M. R. Importância das variáveis intrínsecas e extrínsecas ao varejista como explicação de seu desempenho ao longo do tempo. FACEF Pesquisa, Franca, v.10, n.3, p.309-316, 2007.

BATISTA, M. de L. S. B.; QUINTÃO, P. L.; LIMA, S. M. B.; CAMPOS, L. C. D.; BATISTA, T. J. de S. Um Estudo sobre a História dos Jogos Eletrônicos. Revista Eletrônica da Faculdade Metodista Granbery, Juiz de Fora, n. 3, 2007.

BELLI, S.; RAVENTÓS, C. L. Breve historia de los videojuegos. Athenea Digital, Barcelona, n.14, p.159-179, 2008. 
PINTO, N. G. M.; et al. Análise Comparativa da Evolução das Vendas e do PIB...

BRASIL, A. Jornalismo e videogames: Desafios para a formação profissional e a produção de novos Conteúdos Jornalísticos. Revista Brasileira de Ensino de Jornalismo (REBEJ), Ponta Grossa, v.1, n.10, p.9-49, jun-dez, 2012.

CRUZ JÚNIOR, J. B. da; BAUMGARTEN, M. Z.; PEREIRA, M. F. As melhores práticas de estratégia: o caso da Nintendo Co. Revista FAE, Curitiba, v.11, n.2, p. 114, jul-dez, 2008.

DÍEZ, A. L. Los videojuegos, marcadores de tendencias en El ócio tecnológico. Comunicar, Huelva, n. 27, p. 79-84, 2006.

ETXEBERRIA, F. Videojuegos, Consumo y Educación. Revista Electrónica Teoría de La Educación y Cultura em La Sociedad de La Información, Salamanca, v. 9, n. 3, p. 11-28, 2008.

FONTENELLE, I. A. Novas Mídias e Mercado da Experiência: um estudo da indústria dos videogames. Relatório de Pesquisa - Fundação Getúlio Vargas, São Paulo, 2005.

FRÍAS, J. A. G. La industria Del videojuego a través de lãs consolas. Revista Mexicana de Ciencias Políticas y Sociales, Ciudad de México, v. LII, n. 209, p. 161179, mai-ago, 2010.

GREENE, W. H. Econometric analysis.6 ed. New Jersey: Prentice Hall, 2008.

MCCANN, S. Showdown Systems. Library Journal, New York, p. 73, 2013.

MATSUI, E. K.; COLOMBO, M. A Geração Videogame e o Futuro no Mundo dos Negócios. Revista Científica Eletrônica de Psicologia, Garça-SP, ano V, n. 8, p. 1-8, 2007.

MATTAR, F. N. Pesquisa de marketing: metodologia, planejamento. 6.ed. São Paulo: Atlas, 2008.

MONTEIRO, C. B. Videogames como fonte de análise histórica. O Olho da História, Salvador, n. 16, v. 15, p. 8-17, 2011.

PINHEIRO, C. M. P. Videogames - Do entretenimento à comunicação. Revista Universítária do Audiovisual, São Carlos, 2008. 
PINTO, N. G. M.; et al. Análise Comparativa da Evolução das Vendas e do PIB...

VIAN, G.; MACEDO, E. M. de A. Press Start: Como os videogames influenciam a sociedade contemporânea. In: XVIII Prêmio Exposição da Pesquisa Experimental em Comunicação (Expocom). Cuiabá, 2011.

VIDEOGAME CHARTZ. Yearly Chart Index. Disponível em: <http://www.vgchartz.com/yearly/>. Acesso em: 10 de abr., 2013. 